\title{
Expanding HLRS Academic HPC Simulation Training Programs to More Target Groups
}

\author{
Tibor Döpper ${ }^{1}$ \\ doepper@hlrs.de
}

\author{
Darko Milakovic ${ }^{1}$ \\ milakovic@hlrs.de
}

\author{
Oliver Scheel ${ }^{1}$ \\ scheel@hlrs.de
}

\author{
Bärbel Große-Wöhrmann ${ }^{1}$ \\ grosse-woehrmann@hlrs.de
}

Doris Lindner
lindner@hlrs.de

\author{
Jutta Oexle ${ }^{1}$ \\ oexle@hlrs.de
}

\author{
Sven Slotosch ${ }^{2}$ \\ sven.slotosch@rz.uni-freiburg.de
}

\author{
Michael M. Resch ${ }^{1}$ \\ resch@hlrs.de
}

\author{
Leon Widmaier ${ }^{2}$ \\ leon.widmaier@rz.uni-freiburg.de
}

\begin{abstract}
For a long time, high-performance computers and simulations were of interest only at universities and research institutes. In recent years, however, their application and relevance in a wider field has grown; not only do industry and small and medium-sized businesses benefit from these technologies, but their social and political impacts are also increasing significantly. Therefore, there is an increasing need for experts in this field as well as better understanding of the importance of high-performance computing (HPC) and simulations among the general public. For this reason, the German National Supercomputing Center HLRS has broadened its academic training program to include courses for students and teachers as well as for professionals. Specifically, this expansion involves two projects: "Simulated Worlds," which offers a variety of educational programs for middle and high school students, and the "MoeWE" project with its "Supercomputing Academy" for professionals. These projects complement the center's academic educational focus by addressing the special needs of these new target groups who have otherwise not been able to benefit from HLRS' academic training program. In this paper, we present background concepts, programmatic offerings, and exemplary content of the two projects; discuss the experiences involved in their development and implementation; and provide insights that may be useful for improving education and training in this area.
\end{abstract}

\section{Keywords}

Supercomputer, HPC, Simulation, Numerical methods, Machine learning, Demand oriented school events, Blended learning, High school students, Professionals

\section{INTRODUCTION}

Computer simulation has become an indispensable tool in most fields of science and technology, while simulation results increasingly influence decision making in business, politics, and

Permission to make digital or hard copies of all or part of this work for personal or classroom use is granted without fee provided that copies are not made or distributed for profit or commercial advantage and that copies bear this notice and the full citation on the first page. To copy otherwise, or republish, to post on servers or to redistribute to lists, requires prior specific permission and/or a fee. Copyright $\odot$ JOCSE, a supported publication of the Shodor Education Foundation Inc.

(C) 2021 Journal of Computational Science Education DOI: https://doi.org/10.22369/issn.2153-4136/12/3/2 society. Taking advantage of the opportunities that simulation offers requires not just numerous experts in simulation techniques and high-performance computing (HPC) but also a broad awareness of the nature of simulation in the general public.

While simulations and HPC have been used primarily for academic research in past decades, their impact in industry is now growing as well. In addition to traditional HPC using supercomputers, new topics such as high performance data analytics (HPDA), artificial intelligence and machine learning, and the comprehensive digitalization of industrial production have also been attracting enormous interest. For this reason, there is an increasing need, especially in small and medium-sized enterprises (SMEs), for targeted training of employees.

As a consequence, demand for trainees, students, and young professionals with experience in computing, simulation, and mathematical modeling is also growing. In order to bring young people into contact with the subject as early as possible, the topics of simulation and mathematical modeling are included in German school curricula although for several reasons learning materials and teaching methods have only recently become available. In this context, the teaching content on these topics should complement school experiments in the classroom with the help of computers to convey scientific insight in a vivid way.

In Europe, many HPC centers offer education and training. PRACE's ${ }^{3}$ European training courses were designed for the classroom and are open to participants from industry but are primarily geared to the needs of academic participants. The training courses of the 15 European Centers of Excellence for HPC applications ${ }^{4}$ and the National Competence Centers $(\mathrm{NCCs})^{5}$ in HPC include both face-to-face and online courses and are generally aimed equally at academic participants and participants from industry but often cover specialized topics. The NCCs, which are being established by the EuroHPC Joint Undertaking within the framework of the EuroCC and CASTIEL ${ }^{6}$ initiatives, focus on science, public administration, and both large industry and small and medium-sized enterprises.

\footnotetext{
${ }^{1}$ HLRS, University of Stuttgart, Stuttgart, Germany

${ }^{2}$ Department for E-Learning, University of Freiburg, Freiburg, Germany

${ }^{3} \mathrm{https} / / /$ training.prace-ri.eu/

${ }^{4}$ https://www.hpccoe.eu/eu-hpc-centers-of-excellence 2/

${ }^{5} \mathrm{https}: / / \mathrm{www}$.eurocc-access.eu/

${ }^{6}$ https://www.eurocc-access.eu/the-projects/
} 
There are also numerous providers of online education and training for academics in the IT sector, but only a few specialize in HPC and data science. For example, the University of Edinburgh ${ }^{7}$ and the Johns Hopkins Whiting School of Engineering in Baltimore ${ }^{8}$ offer master's degree programs, and the University of Waikato in New Zealand ${ }^{9}$ specializes in massive open online courses (MOOCs).

As commercial online education providers in HPC and data science, Udemy ${ }^{10}$ and Udacity ${ }^{11}$ offer training videos, the number of participants is unlimited, and the courses are not supervised. NAFEMS ${ }^{12}$ organizes web seminars, mainly on simulation.

In Germany, the School of Advanced Professional Studies (SAPS $)^{13}$ at the University of Ulm and at the Ulm University of Technology has built a tiered online continuing education program for SMEs as part of its "Data Literacy and Data Science" program, and the Hasso Plattner Institute offers free MOOCs and discussion forums on openHPI ${ }^{14}$.

One of the leading HPC centers in Europe, the High Performance Computing Center Stuttgart (HLRS) at the University of Stuttgart, has been operating supercomputers and conducting research in simulation and HPC since 1986. It became Germany's first national supercomputing center in 1996 and is one of the three members of the Gauss Centre for Supercomputing $(\mathrm{GCS})^{15}$. GCS has played a leading role in the establishment of the German National Competence Centers of HPC.

HLRS offers services and support in the field of supercomputing to users from science, research, and industry. It is one of the world's leading research facilities in the fields of supercomputing, data analysis, and cloud computing; participates in the Cluster of Excellence for Simulation Technologies (SimTech) at the University of Stuttgart; and conducts innovative research and solution-oriented technology development.

To meet the increasing demand for HPC expertise, HLRS has offered a successful education program for more than two decades. The program includes classroom courses and workshops on all HPC-relevant topics and is part of national (GCS) and European training programs (PRACE).

Due to their academic focus, however, most HPC training programs do not reach young people and only occasionally reach working professionals. HLRS has filled these gaps by launching two projects. The first, called Simulated Worlds ("Simulierte Welten"), targets students, teachers, and the interested public. It creates awareness of HPC and simulation concepts by implementing the topics into the State of Baden-Württemberg's science, technology, engineering, and mathematics (STEM) curricula.

The second project, "Modular Continuing Education to become an HPC Expert" (MoeWE), established the Supercomputing Academy ("Supercomputing-Akademie") for working professionals. Unlike the above-mentioned offerings, Supercomputing Academy courses are designed in a blended learning format that combines attendance

\footnotetext{
${ }^{7}$ https://www.ed.ac.uk/studying/postgraduate/degrees/index.php?r=site/vi ew\&edition $=2021 \& i d=997$

${ }^{8} \mathrm{https} / / /$ engineering.jhu.edu/ams/data-science-masters-program/

${ }^{9} \mathrm{https}: / / \mathrm{www}$. futurelearn.com/courses/advanced-data-mining-with-weka

${ }^{10} \mathrm{https} / / / \mathrm{www}$. udemy.com/course/deep-learning-und-ai/

${ }^{11} \mathrm{https}: / /$ www.udacity.com/course/data-scientist-nanodegree--nd025

${ }^{12} \mathrm{https} / / / \mathrm{www}$. nafems.org/training/

${ }^{13} \mathrm{https} / / /$ www.uni-ulm.de/en/einrichtungen/saps/projekte/data-literacyund-data-science/

${ }^{14} \mathrm{https} / / /$ open.hpi.de/courses

${ }^{15} \mathrm{https} / / / \mathrm{www}$.gauss-centre.eu/
}

days, self-learning phases, supervised exercises, and web seminars The Supercomputing Academy has become an important component in providing modular continuing education for industry within the framework of the German National Competence Center.

The expansion of HLRS' training program to address these two additional target groups is outlined in Figure 1. Both Simulated Worlds and the Supercomputing Academy focus on the topics of simulation and HPC and benefit from the expertise of HLRS experts. Project teams also designed appropriate programs following communication with experts from industry and schools about needs and expectations. Existing content from academia could also be used for the new target groups but was adjusted in depth and degree of abstraction to suit their needs and preexisting knowledge. Information is also presented using appropriate methods for each case.

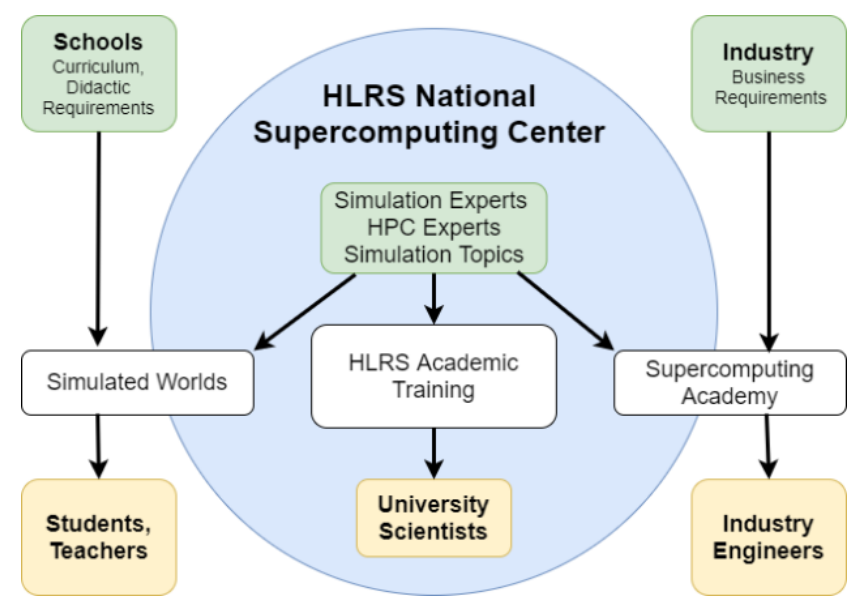

Figure 1. Training activities at the High Performance Computing Center Stuttgart.

In the Section 2, the concepts behind the two programs are presented in detail. Then, in Section 3, the contents of the programs are outlined. In Section 4, the concrete implementation in practice is presented with examples. The conclusion reports on the most important evaluation results and offers an outlook on the further development of both programs.

\section{THE CONCEPTS OF THE TWO PROGRAMS}

Consideration of the specific needs of the two target groups in the development of methods and content used is crucial for the longterm success of both projects, Simulated Worlds and the Supercomputing Academy (MoeWE).

In Sections 2.1 and 2.2, we present the motivations and the process of concept development for Simulated Worlds and the Supercomputing Academy. The goals and special features of each program are described and then compared in Section 2.3. Both projects are united above all by the goal of bringing the topics of HPC and simulation to society. The different target groupsteachers and students on the one hand and professionals on the other-result in different offerings that nevertheless have commonalities. Table 1 in Section 2.3 provides further information on both programs.

\subsection{Simulated Worlds-Events for Schools}

Simulated Worlds has been working since 2011 to bring as many students as possible in the German State of Baden-Württemberg 
into contact with the topic of simulation at least once in their school careers. It also provides teachers in Baden-Württemberg with suitable teaching materials and corresponding training.

When developing a suitable educational enrichment concept, it is important to take characteristics of the relevant school system into consideration. In Germany, after completing four years of common primary education, students go to one of three types of secondary school. The first, called the Gymnasium, corresponds to Level 3 "upper secondary education" of UNESCO's International Classification of Education (ISCED) [15] and aims at preparing students for college and university careers, focusing on logical and analytical skills. For students from grade 6 upwards who attend this type of school, Simulated Worlds has offered a variety of courses since 2011 (presented in an overview in Section 3 and deepened with two detailed examples in Section 4).

The second type of school, called the Realschule, teaches more practically applicable knowledge for professional practice. Simulated Worlds is currently developing content adapted to this curriculum in cooperation with a pedagogical university. The third type of school, the Hauptschule, is less suitable for the thematic goals of the project as its teaching of basic educational content is even less oriented toward the abstract concepts typical of computer science.

Originally, Simulated Worlds was intended to raise awareness of the science of HPC. The elaboration of this idea was carried out with the help of focus groups involving students and teachers who provided input that was used to concretize program goals and implementation strategies. Focus groups rely on a moderated process in which small groups discuss a particular topic in order to articulate as many facets as possible about the topic [19]. In the Simulated Worlds focus groups, participant input resulted in a shift of emphasis from HPC to simulation, a term that would be more descriptive and meaningful for students. Based on the input of the focus groups, the project team expanded and developed flexible, directly applicable and easily adaptable programmatic offerings with a thematic focus on simulation. The project was funded by the Ministry of Science, Research and the Arts of the State of BadenWürttemberg and started in 2011 on a small scale with HPC centers in Stuttgart (HLRS) and Karlsruhe (Steinbuch Center for Computing at the Karlsruhe Institute of Technology). Shortly thereafter, the program launched in cooperation with two model schools. Over the years, they were joined by the HPC Center Ulm (Communication and Information Center of the University of Ulm) and two more model schools. The project team is now composed of interdisciplinary social scientists, mathematics educators, computer scientists, and HPC Ambassadors; full-time teachers in the secondary education sector (Gymnasium) who provide expert insights to the project for three to five hours per week, based on their daily teaching experience.

This multidisciplinary approach connects different areas of knowledge; while scientists at the computing centers develop initial ideas and concepts that are suitable for teaching to students, the HPC Ambassadors advise them on the development of new teaching materials and check content for its compatibility with the official school curriculum and the corresponding knowledge level of the students. The HPC Ambassadors also test the materials in the classroom, present them at other schools, and help to keep the program's offerings up-to-date and thus interesting for students. They are also multipliers of the offerings and help build networks among different teachers and schools.
For teachers, teaching material is particularly interesting if it can be used to fulfill curriculum requirements easily. For example, the STEM subjects in high schools require that 10th grade students "[...] develop systems in increasingly complex contexts and [...] know about the dynamics and interactions in these systems" [14]. For this purpose, they should, for example, understand the importance of "model building and simulation" and how the computer is used as a tool, for example, to simulate dynamic systems [14]. Teachers might have issues with the curriculum because precise instructions, didactic approaches, or examples of simulations are not very concrete. Simulated Worlds addresses the curriculum and the challenges by elaborating material with practical help and develops concrete teaching materials that can be booked by schools in various offerings (see Section 3.1).

Compared to other digital tools, didacticians attested that learning about simulation provides the greatest increase in students' competencies in digital literacy [1]. In addition, simulations can help students visualize a wide range of topics, both in terms of content (e.g., climate simulations, energy transition) and science and mathematics (e.g., growth models, stochastics). They facilitate the recognition of interrelationships and offer alternative ways of representation (e.g., through various graphics) [7]. Furthermore, mathematical modeling allows students to work on problems that are close to their everyday life [8].

Other projects with a similar goal to that of Simulated Worlds, for example, try to bring students to a standard level of knowledge in information technology [4]. It is more beneficial if the first, possibly uniform experiences are created much earlier, namely at school. International projects that target schoolchildren try to familiarize them with programming and computer science $[5,6]$.

Simulated Worlds complements other existing, wide-ranging offerings for students in STEM fields. What distinguishes it, however, is its focus on the complex themes of simulation, HPC, and mathematical modeling. Computers are used as tools, while programming takes a back seat. At the same time, the project implements the curriculum of the schools and thus also addresses their needs. Simulated Worlds supports teachers, enabling them to implement the topics actively and independently in the classroom.

Based on these requirements, each of the offerings of Simulated Worlds includes answers to the following questions:

- Where can scientific simulations be found in everyday life? In which decisions do simulation results have an impact and are thus politically, economically, and socially relevant?

- Why do scientists carry out simulations?

- How do scientists carry out simulations?

- What are the opportunities and risks associated with simulations?

There is a pool of examples that can be used to flexibly embed these questions into the respective teaching topics. Examples include simulations of heat conduction, human behavior during panic, the spread of viral diseases, traffic patterns, or the shift to renewable energy sources (see Table 1, Section 3.1).

In order to make the principles of scientific simulation, supercomputing, and mathematical modeling accessible to students and teachers, the project team primarily offers free classroom events that can be held either in schools or at computing centers. Depending on the location, different emphases are then set (see Section 3.1). Similarly, the duration and level of detail of the faceto-face offerings is very scalable, ranging from 90-minute school 
double lessons to half-day workshops, such as the so-called do-IT day, to a six-month scholarship. Section 3.1 describes these offerings and their content in more detail, and Section 4 uses concrete examples - simulations of heat conduction and a commuter train system - to show how young people can try things out for themselves in the do-IT day and in the scholarship.

\subsection{Supercomputing Academy-Blended Learning for Professionals}

Since April 2018, the Supercomputing Academy ${ }^{16}$ has been offering professionals a part-time, modular, continuing education program that enables them to develop expertise in HPC. The program is aimed at computer scientists, engineers, and IT-oriented career changers. The focus is on employees of small and mediumsized enterprises (see Table 1, Target groups). The aim is to enable participants in the Supercomputing Academy to independently develop solutions for problems in the field of HPC after qualification.

The continuing education program is organized in a blended learning format. The combination of online and offline phases allows maximum time flexibility and location independence, making it possible for participants to learn at an individual pace whenever and wherever they find time alongside work and family commitments. Weekly virtual seminars focusing on previous learning units provide some structure to the learning process and enable learners and teachers to exchange views on the learning material from the previous week. The assignments and exercises are discussed intensively and help the learners to keep up with the curriculum.

Each module (see Figure 3) starts and ends with an attendance day, where speakers from industry and HLRS introduce or conclude the module topics with technical presentations. All learning materials are accessible via an open-source learning management system, the Integrated Learning, Information and Work Collaboration System (ILIAS) ${ }^{17}$. Practical exercises (hands-on) that require computing resources are conducted on the HPC training cluster, a scaled-down version of an HLRS production system. Each participant who has completed the exercises and virtual seminars contained in a course module receives a qualified certificate of participation. Following the successful completion of a test, graduates receive a certificate of achievement.

Experts at HLRS are familiar with current scientific developments in HPC and simulation. However, in order to incorporate the viewpoint of industry - the target group of this program-into the continuing education program, and to enable a transfer of knowledge into daily work, identifying the needs of businesses and addressing them in the curriculum of the continuing education program is of vital interest. Roundtable discussions involving HLRS experts, scientists, and industry experts-so-called expert workshops - as well as interviews with industry experts were held to determine the need for HPC know-how in industry. In addition, the requirements, topics, and learning objectives were outlined. The identified requirements form the basis for the learning content,

\footnotetext{
${ }^{16}$ The universities of Stuttgart, Freiburg, and Ulm in Germany and SICOS BW GmbH have joined forces in the MoeWE project to found and establish the "Supercomputing Academy" based at HLRS. The accompanying project MoeWE (2016-2021) was funded by the Ministry of Science, Research and the Arts of the State of Baden-Württemberg and the European Social Fund (ESF).

${ }^{17} \mathrm{https}: / / \mathrm{www} . \mathrm{ilias} . \mathrm{de} / \mathrm{en} /$. ILIAS is widely used in Germany as a learning management system and is constantly being further developed by the ILAS community.
}

which is created and continuously developed by HLRS experts. The module contents cover all HPC-relevant topics (see Table 1, Modules).

The competencies to be acquired are formulated in concrete, actionoriented, and verifiable terms and translated into learning objectives $[12,17]$. Bloom's taxonomy of learning objectives is used for operationalization [2, 3]. Learning objectives have different functions. They guide teaching and learning processes in terms of content. They help to reflect and plan the instructor's intentions. Finally, they also serve to review the achievement of objectives and to clarify the way forward [18].

The "3-2-1 model of didactic elements in hybrid learning arrangements" [11] is used to develop the structure and content of each module. This model provides guidance for the organization and design of learning arrangements in a blended learning environment. It can be used to identify three mandatory elements, two supplementary elements, and one optional element, as described below.

The content of the three mandatory elements is determined by the learning objectives. Orienting information for each module and for the lessons within a module are provided on the learning platform. They are supplemented by learning control tasks and enriched by exercises. The exercises require the participants to apply the acquired knowledge, to demonstrate mastery of it, and to use it in a new context. Thus, the exercises promote the ability to transfer and apply what has been learned to other situations [16]. Once participants have completed all the exercises, they receive a qualified certificate of participation at the end as proof of the work they have done.

During the online phase, learning is self-directed in terms of time, scope, and speed of the learning process. It promotes selfregulation, and metacognitive processes such as monitoring and regulation can be stimulated [16].

The two supplementary elements, communication and cooperation, are established at a social event organized on the face-to-face day that gives participants a chance to meet one another and to make first contact with the instructors. In the weekly virtual seminars, the communication element is strongly emphasized. The lecturers reflect on the learning material of the previous week and give the participants the opportunity to ask questions and share and discuss problems. The discussion session is moderated by the module supervisors. Opportunities for cooperation are provided via an online forum. Here, participants have the opportunity to support each other when problems arise and to help their partners with suggestions for solutions. These dialogical and dialectical interactions can increase motivation and support the acquisition of knowledge and skills [22].

The optional element in the modules is the test. It takes place on the last attendance day of each module. Participants who complete the exam successfully receive a certificate as confirmation.

To increase motivation for the test and to recognize achievements, four awards have been introduced:

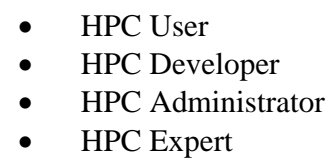

Participants who have successfully completed three modules and the corresponding tests receive an award reflecting their chosen direction (HPC user, developer, or administrator). Participants who 
successfully complete two more modules receive the HPC Expert award (see also Table 1, Award). More detailed information about the modules and awards can be found in Section 3.2.

The effort required to set up this continuing education program amounted to six and a half full-time positions during the entire four years. Coordination, didactics, conception, production, and implementation required about $3 / 4$ of the positions. Dissemination and contact management, acquisition, and public relations accounted for $1 / 4$.

\subsection{Profile of Both Programs}

Simulated Worlds and the Supercomputing Academy are united above all by the goal of bringing the topics of HPC and simulation to society. The different target groups - teachers and students on the one hand and professionals on the other-result in different offerings that nevertheless have commonalities. Table 1 summarizes both programs.

\section{CONTENTS OF THE TWO PROGRAMS}

In the previous section, the concepts of Simulated Worlds and the Supercomputing Academy were presented. Both project teams developed their offerings using an exploratory approach in which they directly involved the respective target groups through focus groups and expert workshops, respectively.

Section 3.1 will provide overviews of their content. Two examples of the contents are then explained in detail in Section 3.2.

\subsection{Contents of Simulated Worlds}

In order to reach as many schools as possible in BadenWürttemberg, diverse formats with varying degrees of difficulty are necessary. The offerings of Simulated Worlds are based on the so-called "knowledge mountain" (see Figure 2) according to which the formats can be assigned to three knowledge levels; the first is called "Basic Knowledge," the second "Exemplary Knowledge," and the third "Detailed Knowledge." All formats can be offered to interested schools individually as they are independent of each other in terms of prior knowledge. The formats differ in duration, depth of knowledge, and target group (see Table 1, Target group). All three levels of knowledge are explained here with examples.

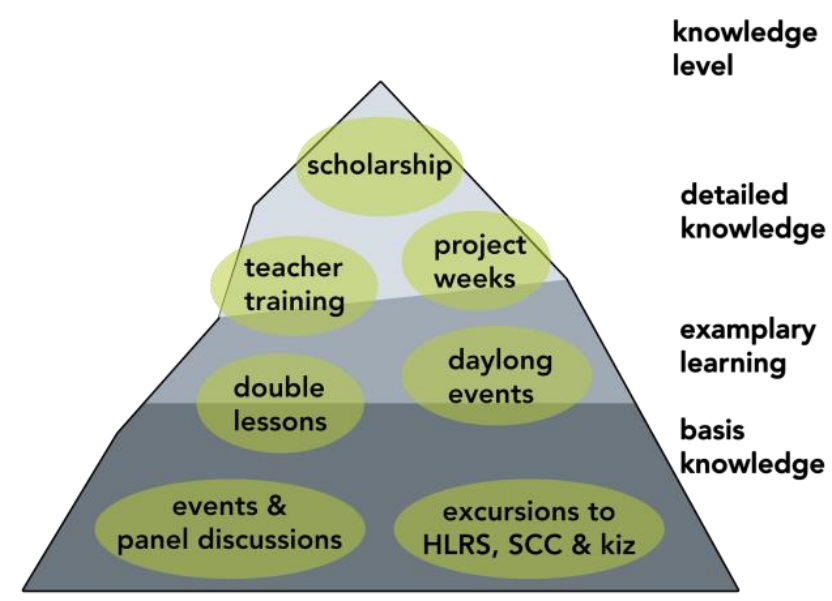

Figure 2. "Knowledge Mountain"—Locating the offerings of Simulated Worlds.
Table 1. Comparison of the programs of Simulated Worlds and Supercomputing Academy.

\begin{tabular}{|c|c|}
\hline Simulated Worlds & Supercomputing Academy \\
\hline \multicolumn{2}{|l|}{ Objective } \\
\hline $\begin{array}{l}\text { To impart knowledge about } \\
\text { HPC and simulation }\end{array}$ & $\begin{array}{l}\text { To impart knowledge about } \\
\text { HPC and simulation }\end{array}$ \\
\hline \multicolumn{2}{|l|}{ Target group } \\
\hline $\begin{array}{l}\text { Teachers and students } \\
\text { (especially at high schools), } \\
\text { interested public }\end{array}$ & $\begin{array}{l}\text { Working professionals: } \\
\text { System administrators, } \\
\text { software developers, users } \\
\text { from industrial and academic } \\
\text { fields }\end{array}$ \\
\hline \multicolumn{2}{|l|}{ Offerings / Modules } \\
\hline $\begin{array}{l}\text { Topic-specific offerings of } \\
\text { different duration: panic } \\
\text { simulation, spreading of } \\
\text { diseases, do-IT day on heat } \\
\text { conduction, bridge simulation, } \\
\text { crane simulation, etc. }\end{array}$ & $\begin{array}{l}\text { Advanced training to become } \\
\text { an HPC expert: } \\
\text { Parallel Programming, } \\
\text { Simulation, HPC cluster, } \\
\text { Performance Optimization, } \\
\text { Economics and Sustainability, } \\
\text { Visualization, Data: } \\
\text { Management \& Analysis, } \\
\text { Basics }\end{array}$ \\
\hline \multicolumn{2}{|l|}{ Formats } \\
\hline $\begin{array}{l}\text { Attendance events: } \\
\text { Double lessons, lectures, day } \\
\text { sessions, advanced training, } \\
\text { project week, scholarship }\end{array}$ & $\begin{array}{l}\text { Blended Learning: } \\
\text { Face-to-face days: kick-off \& } \\
\text { closing events; online phase } \\
\text { with weekly virtual seminars. }\end{array}$ \\
\hline \multicolumn{2}{|l|}{ Self-study } \\
\hline $\begin{array}{l}\text { In the scholarship besides } \\
\text { meetings with supervisors }\end{array}$ & During online phase \\
\hline \multicolumn{2}{|l|}{ Duration per module } \\
\hline $\begin{array}{l}\text { Depending on module: } \\
90 \text { min (double hour) to } 6 \\
\text { months, each } 3 \text { h per week } \\
\text { (scholarship) }\end{array}$ & $\begin{array}{l}\text { Per module: } \\
12 \text { weeks, each } 10 \mathrm{~h} \text { per week }\end{array}$ \\
\hline \multicolumn{2}{|l|}{ Certification / Award } \\
\hline $\begin{array}{l}\text { Certificate at the end of the } \\
\text { support scholarship } \\
\text { Certificate of participation for } \\
\text { teachers after advanced } \\
\text { training }\end{array}$ & $\begin{array}{l}\text { Certificates } \\
\text { Qualified certificate of } \\
\text { participation } \\
\text { Awards: HPC administrator, } \\
\text { HPC user, HPC developer } \\
\text { (three modules) } \\
\text { HPC expert (five modules) }\end{array}$ \\
\hline \multicolumn{2}{|c|}{ Learning progress documentation } \\
\hline $\begin{array}{l}\text { Learning journal in the } \\
\text { scholarship }\end{array}$ & $\begin{array}{l}\text { ILIAS: Learning progress } \\
\text { tracking + learning control } \\
\text { questions }\end{array}$ \\
\hline
\end{tabular}

\subsection{1 "Basic Knowledge"-Lectures and Excursions to Computing Centers}

The events that belong to the Basic Knowledge category serve as an introduction to the topic and are offered at many schools. For students and teachers, these classroom events are their first contact with the topic of simulation. 
Lectures by HPC experts on the topics of simulation and HPC, which can be booked by schools, are popular. Participants learn about current scientific projects and can ask questions about the state of research and engage in conversations with scientists. The HPC experts are informed about the level of knowledge of the classes before the lecture so they can better adapt the level of the lecture to the school classes (grades 8 to 10).

In addition, school classes can visit the HPC centers and receive a guided tour of the computer hall. Additionally, at HLRS, the CAVE can be toured-a walk-in projection chamber where groups of people can experience $3 \mathrm{D}$ visualizations simultaneously.

These offerings for schools are complemented by evening lectures for the interested public that are organized by the project team. Here, simulation experts provide insight into current research topics and answer questions from participants. Thus, although the focus of Simulated Worlds is on teachers and students, addressing interested members of the public is a supplementary activity.

\subsection{2 "Exemplary Knowledge"-Double Lessons and Daylong Events}

This level of knowledge transfer combines academic science with everyday examples to teach simulation in a comprehensible way. To promote deeper understanding, a hands-on phase is always integrated, in which students run a simulation themselves. Here, Simulated Worlds again offers two formats: double lessons and doIT days.

In a double lesson, a member of the project team introduces a specific topic on simulation, e.g., the spread of a disease or the development of a panic situation in a nightclub. A short lecture outlines what a simulation is, how it works, and what risks are associated with it. Afterwards, in the hands-on phase (approx. 45 minutes), the students are allowed to run a simulation themselves using a program such as NetLogo ${ }^{18}$. This offering is designed for school classes from grades 7 to 10 . The level of difficulty varies depending on the age of the students.

The do-IT day is an approximately four-hour workshop, in which students gain deeper insights. The workshop provides a brief overview of computer-aided simulation and its many possible applications in the worlds of work and science. Due to the more complex requirements in the hands-on phase (e.g., programming in Python), students in grades 9 through 11 are targeted here.

Simulations are introduced as the fundamental link between theory and experiment in science. The following form of the simulation cycle is explained to them:

1. In modeling, parts of reality or a physical state are described mathematically.

2. To obtain a prediction of the future state of the object, mathematical equations are solved in complex or repeated cases with the computer.

3. The result of the calculation is compared with the observed reality.

4. Relevant differences lead to a change in the modeling. Thereupon, the cycle is restarted to improve the match.

Further details on the tasks of the do-IT day can be found in Section 4.

\footnotetext{
${ }^{18}$ For all programs, the project team makes sure to use open-source programs to minimize the financial burden on schools and enable them even to host such an event again themselves.

Link: https://ccl.northwestern.edu/netlogo/
}

\subsection{3 "Detailed Knowledge"-Scholarship, Project Weeks, Internships, Training for Teachers}

The aim of Detailed Knowledge is to provide students and teachers with in-depth insights into the topics of simulation and HPC. Students, in particular, deal intensively with a specific problem over a longer period of time and try to solve it independently. Teachers are provided with extensive learning and teaching material so that they can implement the topic of simulation themselves in the classroom.

Students in the 11th grade with a special interest in STEM fields can receive a scholarship at a high-performance computing center. The scholarship lasts about six months, during which approximately ten students spend three to four hours a week working on a topic of their choice in addition to their classes. The topics are provided by employees of the respective computing centers.

The aim of the scholarship is to give the students insights into the work of a high-performance computing center. In the process, they also learn how to work scientifically. The work in the scholarship is primarily characterized by independent work on a project. This includes research as well as familiarization with new programs, e.g., by means of tutorials.

Organizationally, there are three mandatory, official meetings with all students: a kick-off meeting; an intermediate meeting to address problems and present the current status of their projects; and a final, official presentation of their results to a public audience (parents, friends, teachers, etc.).

During the scholarship, students keep a learning journal [21] in which they record their assignments, their positive and negative experiences, and how they overcame challenges. Students are guided by questions that provide direction. At the end, they draw a personal conclusion. The main goal of the learning journal is for students to reflect on their work experiences and their methods of problem solving. This experience is generally transferrable to the classroom, where students also use the skills they have acquired during the scholarship. At the same time, this experience should prepare them for future working situations, e.g., in their studies at university. A concrete example of a scholarship can be found in Section 4.

Another option for delivering Detailed Knowledge occurs during project weeks for students held at computing centers. Here, too, particularly interested students from grades 10 and 11 can work on a scientific problem. An additional option is through internships, where 9th or 10th grade students are asked to spend a week doing an internship at a company. Students spend time in a department at a supercomputing center and are assigned to a specific project, gaining insight into the process and tasks that projects entail as well as general information about the workings of a data center.

The fourth offering created to deliver Detailed Knowledge is aimed at teachers in STEM fields. Here, advanced training courses are offered, which are conducted by HPC Ambassadors together with scientists. In these one-day or multi-day training courses, participants receive an introduction to simulations and programming with a programming language suitable for students. Procedures and teaching materials are presented as examples so that teachers can independently integrate the topic of simulation into their lessons. 


\subsection{Contents of the Supercomputing Academy}

The Supercomputing Academy has divided its offerings into seven modules. During the expert workshops with HLRS and industry experts, three main target groups were identified for the Supercomputing Academy. These are users of simulation programs, developers of simulation programs, and IT administrators interested in HPC (see also Table 1). Professionals in all three target groups can earn the corresponding awards already mentioned in Section 2.2 if they successfully complete the associated modules plus one additional module of their own choosing including the related tests. The seven modules are shown in Figure 3 in combination with the awards to be achieved. Their contents are briefly presented below.

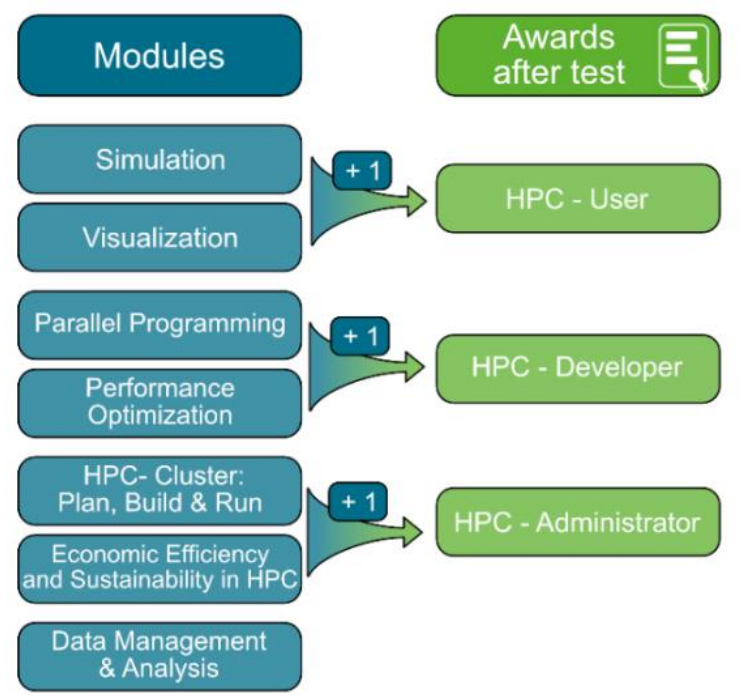

Figure 3. The modules and their assignment to the HPC User, HPC Developer, and HPC Administrator awards. "+1" denotes an additional module of free choice.

The Simulation and Visualization modules are primarily aimed at users of simulation programs.

The Simulation module is one of the central modules of the Supercomputing Academy. Its first learning unit presents the entire simulation cycle while focusing on the heat conduction equation. In addition to providing an introduction to the topic, the purpose of this learning unit is to establish a common knowledge base among participants (see Section 4.1.2 for more details). In the subsequent learning units of the Simulation module, the fundamentals of computational fluid dynamics (CFD) and structural mechanics are provided. The Navier-Stokes equations and the equations of structural mechanics are introduced, and their discretization methods are explained. Finite difference (FDM), finite element (FEM), and finite volume (FVM) methods are introduced with simple examples and practiced using provided implementations.

Subsequently, the numerical methods used in the simulationsprimarily methods for solving systems of linear equations-are covered with emphasis on HPC-specific aspects, tested on the HLRS training cluster, and compared. The topics covered in this module are completed by learning units on particle-based methods and on molecular dynamics simulations as well as a discussion of the societal impact of simulation.

The module Simulation is followed by the module Visualization that consists of three topics. In the first topic area, "Introduction and Motivation," students learn about the many uses of visualizing measured data and data computed in simulations in combination with virtual reality (VR) and augmented reality (AR).

In the second topic area, "Virtual and Augmented Reality in Technical-Scientific Visualization", topics such as human perception, colors and vision, graphics hardware, and interfaces are covered in depth. Finally, in the third topic area, "Interactive Remote Visualization on Clusters," interactive exercises using the open-source programs ParaView ${ }^{19}$ and COVISE ${ }^{20}$ for technical scientific visualization are conducted on the HLRS training cluster.

Completion of the Simulation and Visualization modules, as well as one additional module of free choice, is mandatory for earning the HPC User award (see also Figure 3).

For software developers who want to parallelize and optimize numerical methods and simulation programs, the Supercomputing Academy offers the modules Parallel Programming and Performance Optimization.

After an introduction to parallel thinking and the parallelizability of algorithms and software, participants in the Parallel Programming module learn the central concepts and commands of OpenMP and practice them using simple programs. This is followed by learning units on MPI for beginners and advanced users including exercises focusing on parallel $\mathrm{I} / \mathrm{O}$ and hybrid programming. Since the focus of the module is on the use of software on HPC clusters; the topics of scalability, domain decomposition, and load balancing as well as parallel design patterns, heterogeneous computing systems, and graphics cards are also covered.

High-performance computing is a matter not only of running parallelized software on HPC clusters and supercomputers but also of emphasizing its efficiency, i.e., its optimization for the available hardware. Participants in the Performance Optimization module, another central module of the Supercomputing Academy, learn about this.

The Performance Optimization module consists of four parts. In the first, the basics regarding CPUs and the parallel programming models MPI and OpenMP are provided, also serving as prerequisites for understanding the following parts. The second part introduces the methodology of performance optimization.

In the third part, "Node-Level Performance Optimization", important aspects of performance optimization at the compute node level are introduced including vectorization and the importance of efficient data transport between main memory, caches, and the processor. After the presentation of modern processor and memory microarchitectures, the functionality of the AVX units and central processes such as memory allocation are analyzed in provided benchmarks on the training cluster. The fourth part, "Optimization of Communication," deals with the analysis and optimization of data transport between computing nodes.

Participants must successfully complete the Parallel Programming and Performance Optimization modules - in addition to a third module of free choice - to receive the HPC Developer award (see Figure 3).

For system administrators - and for users and software developers with an interest in building HPC clusters - the module HPC Cluster: Plan, Build, Run is suitable. Its focus is on hardware. In

\footnotetext{
${ }^{19}$ https://www.paraview.org

${ }^{20}$ https://www.hlrs.de/covise
} 
the first part, "Fundamentals," participants learn about the main components of any HPC cluster: compute nodes, a highperformance data network, and data storage. In addition, information is provided on operating systems, compilers, libraries, and software management. In order to be able to discuss performance aspects with software developers, administrators also learn basic performance facts.

Building on these fundamentals, the second part of the module involves designing an HPC cluster on paper and learning about aspects of its technical integration into a company. Additional knowledge about batch systems, monitoring, and IT security that are necessary for the integration of the cluster into other IT systems and for its operation are taught in the third part of the module. The most important matters concerning virtualization, containerization, and cloud computing are compiled in the fourth part.

Business issues surrounding HPC clusters are the subject of the module, "Economics and Sustainability," designed for IT administrators. This module looks at business management and environmentally sustainable aspects of HPC and explains why business viability and sustainability are not contradictory. The central question of this module is how the goals of efficient computing and sustainability can be achieved simultaneously.

In the topic area, "Economic Efficiency," the basics of investment decision-making and cost accounting are introduced, as well as multi-criteria decision support. The knowledge acquired is then applied to the HPC operating models "in-house cluster" and "cloud utilization" as well as mixed forms of the two approaches. The basics of these operating models and the associated costs and dependencies are explained.

The module also provides an introduction to the issue of sustainability. This includes providing insights into environmental certifications according to ISO 14001 and ISO 50001 as well as the standards EMAS $^{21}$ and the Blue Angel $^{22}$ for energy-efficient data center operation. Other important topics include power supply and efficient cooling as well as sustainable procurement and end-of-life management. Participants learn how closely profitability and sustainability are linked in the various practical exercises.

Successful completion of the HPC Cluster: Plan, Build, Run; Economics; and Sustainability in HPC modules and one elective module are required for the HPC Administrator award.

The seventh module, "Data: Management and Analysis," is of interest to all three target groups and is a very popular elective module. It consists of two topic areas. The first topic area, "Management," contains an introduction to data and familiarizes participants with the basics. They are also introduced to the technical basics, ontology, and model design of metadata and methods and tools for handling data in repositories. Finally, the topics of dark data and data accountability are addressed.

The second topic area focuses on the analysis of large amounts of data using artificial intelligence and HPC. For this purpose, current container technologies, database technologies, and explorative data analysis are introduced. Finally, the basics of machine learning are covered, introducing participants to the topic of neural networks and deep learning on HPC systems. As part of emerging fields, exploratory data analysis is presented in Section 4.2.

\footnotetext{
${ }^{21}$ https://www.emas.de/en

${ }^{22} \mathrm{https} / / / \mathrm{www}$.blauer-engel.de/en/products/electric-devices/data-centers
}

Participants who successfully complete five modules will receive the HPC Expert award (see Section 2.2).

In contrast to students, the participants in the Supercomputing Academy are a very heterogeneous group of professionals with individual prior knowledge, experience, preferences, and goals. In order to achieve an approximately homogeneous learning group, the necessary prior knowledge is communicated to prospective students in advance of the start of each course module. This gives them the opportunity to catch up on missing knowledge or to refresh their knowledge. This ensures that participants can successfully complete the modules.

Linux knowledge is a prerequisite in all modules, as highperformance computers are only operated with Linux operating systems. In addition, basic knowledge of computer hardware is beneficial for all modules. For some modules - Simulation, Parallel Programming, and Performance Optimization-programming knowledge in Fortran or $\mathrm{C}$ is also a prerequisite. Some modules also require special prior knowledge. For example, the Simulation module expects a basic understanding of vector analysis and linear algebra from the participants.

\section{TRAINING AND TEACHING MATERIALS}

The following two examples, focusing on simulations of heat conduction and suburban train delays, provide a deeper insight into the contents of the Supercomputing Academy and Simulated Worlds. In each case, first the similarities and then the differences in the level of detail and procedure are presented.

\subsection{Heat Conduction}

Both the do-IT day on heat conduction developed by Simulated Worlds and the Simulation module of the Supercomputing Academy start with the presentation of the simulation cycle and explain it using the heat conduction equation (cf. Section 3). This equation has the advantage that it can be used to show principles that are essential for simulations (e.g., spatial discretization and the role of boundary conditions), and at the same time it is comparatively simple.

\subsubsection{Do-IT Day on Heat Conduction from Simulated Worlds}

For many students, computer simulations are initially abstract and difficult to conceptualize. In order to make simulation more vivid, the do-IT day focuses on the visualization of heat conduction in a real classroom (see Figure 4 and Figure 5). Didactically, creating computer simulations that visualize the flow of thermal energy provides a very good opportunity to teach otherwise abstract physical concepts [23] and apply them to things that can be experienced by students.

Due to the need to adapt the content of the do-IT days to the knowledge that students have previously acquired in mathematics and physics classes, only the steady-state heat conduction equation is used. Necessary knowledge about partial differential equations is introduced and explained.

The theme of the do-IT day makes it possible to create a sequence of tasks that promote step-by-step learning by having the simulation approximate the real situation. Starting from the thermal equilibrium between walls and windows, additional heat sources (radiators, red rectangles in Figure 4) and then heat sinks (air conditioning, light blue in Figure 4) are introduced into the twodimensional space. 


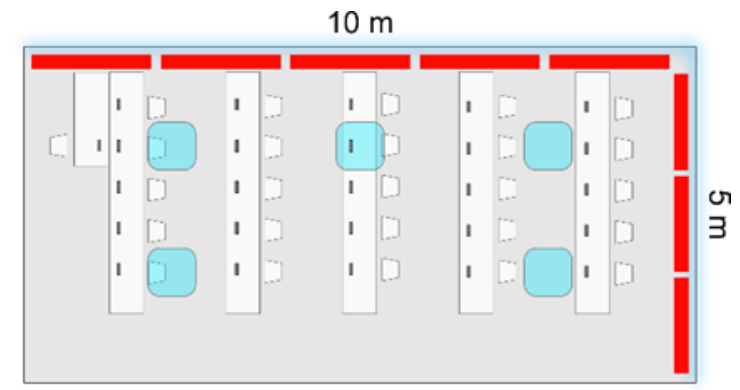

Figure 4. Sketch of the classroom.

The simulation and visualization code is written in Python. Since few students learn this computer language in schools, the do-IT day introduces the basics in about 30 minutes. Furthermore, the code is not completely written by the students, but they are given a code framework with gaps at critical points similar to a cloze. In this way, students' attention is focused on implementing modeling decisions rather than producing many lines of code. An example of the final output after all steps is shown in Figure 5.

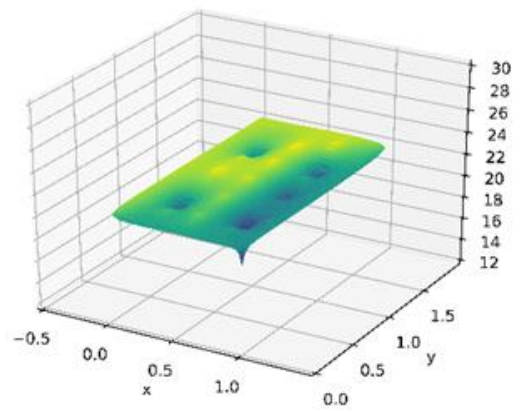

Figure 5. Visualization of the static temperature field in the classroom as a 3D heat map (z-axis in degrees Celsius).

After the simulation, the students reflect on and compare their simulation results, discussing the shortcomings and inadequacies of their models. Furthermore, they can test the limits of the computer hardware used by maximizing the spatial resolution.

\subsubsection{Learning Unit "The Simulation Concept" of the Supercomputing Academy}

The objectives of the ten-hour learning unit, "The Simulation Concept," at the beginning of the Simulation module are to illustrate the simulation cycle by means of a real technical and engineering problem and to create a common knowledge base among the participants by introducing important concepts and procedures.

At the beginning of the course unit, the problem is introduced: A windowpane is to be installed in a concrete wall using an aluminum profile. The question arises whether, under the given climatic conditions, a cold bridge is created that promotes mold growth on the inside of the wall. In this case, the aluminum profile would have to be thermally insulated against the wall. This question determines the subsequent identification of the physical quantities involved and the physical-mathematical modeling - in this case, the heat conduction equation with suitable boundary conditions.

Now, the time-dependent heat conduction equation in three dimensions and its spatial and temporal discretization are explained. Furthermore, Dirichlet and von Neumann boundary conditions, the elementary solution methods (explicit and implicit Euler method), and the Courant-Friedrichs-Lewy number (CFL number) are introduced.

This is concretized in the subsequent exercise and applied to a onedimensional example: a windowpane with constant temperatures on the inside and on the outside. The participants calculate the temperature distribution of the pane. Since only three support points are used, this task can be solved with a calculator. It corresponds to the third level of Bloom's taxonomy (application).

Then, participants are provided with a Fortran program that calculates the temperature distribution in the above-mentioned concrete wall in one dimension. The participants fill in gaps in the program code (Bloom's Taxonomy Level 3). The correctness of the code is verified by the correct temperature calculated at a given point in the wall. The program can be run by participants on the training cluster or on their laptops.

In further tasks, two variants of the code are examined, showing variations in what is called sustained performance. These observations and their explanations lead to the topics of the following learning units.

The author of this learning unit has used commercial software to run a simulation that expands the system boundaries to include the entire window, the aluminum profile, and the wall, as well as areas of the interior (all two-dimensional). The graphical outputs of this simulation are provided to the participants, and the evaluation of the time-dependent temperature field using ParaView is explained. The result of the simulation is related to the present problem described at the beginning; this closes the simulation cycle.

\subsection{Analysis of Public Transport Data}

In another unit, an exploratory data analysis is used to analyze Stuttgart commuter rail ("S-Bahn") data to identify and predict correlations that lead to delays. The purpose of this example is to deal with a given data set, i.e., data manipulation and data preparation. Thus, HPC is connected with data science. In addition to machine learning, the focus is on pre-processing and feature engineering. The machine learning pipeline (train, validate, test) and machine learning performance optimization are used.

The main question to the participants is whether the given data set makes it possible for travelers to better plan their travel in the Stuttgart "S-Bahn" using machine learning or perhaps deep learning. Participants approach the solution by completing tasks that facilitate recognition of the correlations and enable the analyses to be carried out. The intensity and duration of the exercises are adapted to the target group.

\subsubsection{Scholarship "S-Bahn” Delay from Simulated Worlds}

The example is worked on by students in the context of the sixmonth scholarship of Simulated Worlds and is thus on the level of the Detailed Knowledge of the Knowledge Mountain. During the scholarship, meetings are held at HLRS at regular intervals in which HLRS staff members present the required theory. Following this, students have the opportunity to present their progress and problems and receive direct help from the HLRS employees.

During the course of the scholarship, students first familiarize themselves with the software systems used (Python, Docker, Jupyter Notebook) and conduct independent research to analyze the data. They then prepare the data, learning about different approaches for doing so. To get a better overview and deeper 
understanding of the data, students then perform statistical analysis (minima, maxima, averages, standard deviations of delays of different commuter rail lines, and box plots of events). Up to this point, students can list and name what they have learned as well as explain and summarize it.

In preparation for the next steps, students receive an introduction to machine learning from the experts including explanations of how machine learning algorithms work. In addition, the use of classification and regression algorithms to calculate delay forecasts and the extension of the model by additional data sets are explained. The latter are, for example, weather data and data on high traffic volumes caused by large public events such as festivals.

In the last phase, the students have the additional opportunity to apply what they have learned by independently calculating the "SBahn" example on a compute cluster at HLRS, enabling them to establish a first contact with HPC.

\subsubsection{Example "S-Bahn" at the Supercomputing Academy}

At the Supercomputing Academy, the commuter rail ("S-Bahn") example is part of the module, "Data: Management and Analysis." The total duration of the module is 12 weeks, of which two weeks are devoted to this example. In the four weeks preceding the "SBahn" example, relevant theory is introduced and illustrated with two other examples. Participants are assumed to have prior knowledge in using Python and tools confidently. The entire "SBahn" example is run on the training cluster. In two virtual seminars, the participants exchange information and results with the experts and can discuss open questions.

During the "S-Bahn" unit, the question to be answered is whether it is possible to achieve the goal of a minute-by-minute prediction of "S-Bahn" arrivals using machine learning. To determine the answer, participants follow a guided approach to perform an exploratory analysis, make a first interpretation, and then extract first simple statistical values for the delay-all done using Python. This learning objective corresponds to the first and second levels of Bloom's Taxonomy, knowledge and understanding.

In the "S-Bahn" example, the participants are confronted with problems, e.g., the data set is quite sparse, and the initial feature set is small. Pre-processing and feature engineering clean up noisy data in a first step. In the next step, some data preparation is performed, such as data augmentation and data fusion. Before running the model, linear relationships are determined with a correlation map. After the model is run, unnecessary features that reduce model performance are filtered out. These learning objectives correspond to the third level of Bloom's taxonomy, application.

Predicting train delays with machine learning involves supervised learning using a set of features called labels. This allows the use of (linear) regression models to predict a delay with high accuracy. Building these models is a difficult task for participants because nonlinear relationships may go undetected or features may be missing. From a set of features, participants predict a discrete label, e.g., delay yes or no. To do this, participants use a variety of tools. This is the fourth level of Bloom's taxonomy, analysis.

For post-processing and optimizing the prediction of commuter rail delays, participants are asked what options are available to improve the model. Possible solutions include choosing different combinations of features or analyzing the impact of ratio training versus test data (learning curve). This corresponds to the fifth and sixth stages of Bloom's Taxonomy, synthesis and evaluation.

\section{RESULTS}

For quality assurance purposes, the offerings of Simulated Worlds and the modules of the Supercomputing Academy are regularly evaluated. Due to the different structures of the two programs, the methods used for this differ in detail.

\subsection{Evaluation Results of Simulated Worlds}

Due to the wide range of different characteristics, Simulated Worlds evaluates its offerings using various methods to ensure and continuously improve quality. In addition, parts of the programe.g., the teacher training courses - are subject to continuous quality control by the state of Baden-Württemberg; training courses must first be approved by the Center for School Quality and Teacher Education Baden-Württemberg (ZSL) and have their own evaluation questionnaire at the end of the events. Furthermore, the quality of the courses is checked and, if necessary, improved by continuous feedback from didactic experts, both internally and externally. Internal experts are the teachers employed in the project, the HPC Ambassadors. The external ones are the active teachers, who are always present as observers during programming conducted in schools and classes or are participants of a further training.

In addition, the activities of the project are made evaluable through documentation of the implemented offerings. Table 2 summarizes the third, three-year funding phase of the project with 53 one-day events, 9 project weeks, and 8 double lessons as an example.

Table 2. Overview "Simulation Package" of the third funding phase.

\begin{tabular}{|l|c|c|c|c|}
\hline Module & Year 1 & Year 2 & Year 3 & Total \\
\hline Daylong events** & 13 & 24 & 16 & 53 \\
\hline Project weeks** & 3 & 2 & 4 & 9 \\
\hline Scholarships* & 22 & 24 & 20 & 66 \\
\hline Double lessons** & 2 & 3 & 3 & 8 \\
\hline Internships* & 6 & 7 & 7 & 20 \\
\hline Teacher trainings* & 47 & 61 & 21 & 129 \\
\hline Lectures, final events ** & 7 & 13 & 5 & 26 \\
\hline
\end{tabular}

Notes: As of June 29, 2021; * Number of participants; ** Number of events; Source: Own representation.

Standardized questionnaires were used for the evaluation of the do-IT day program. In the case described of the do-IT day on heat conduction (see Section 4.1.1), fourteen participating students between the ages of fifteen and seventeen were surveyed. $57 \%$ of them were female and $43 \%$ male.

The do-IT day was rated very good by $35 \%$ of the participants and good by $65 \%$. In response to the open question of which parts of the workshop they particularly enjoyed, the most frequent response was the opportunity to program (four times). Getting a simulation to run themselves, rather than just listening to a lecture, was specifically liked by three participants. It was also emphasized that this type of workshop gives students an idea of what it will be like to work with simulations and computers at a university.

For the (didactic) preparation of such a workshop, it is always a significant challenge for Simulated Worlds organizers to flexibly adapt the schedule to students' individual abilities and needs by including or excluding additional tasks (such as basics of Python programming or offering additional tasks for some students). 
The scholarship also shows evidence of successful use of this strategy. Over the years, more and more schools from the same area have applied. Among the successful applications through 2021, the scholarship had 44 students from 19 high schools in the Stuttgart area; 45 students from 20 high schools in the Karlsruhe area; and, already in its first year of the offering in Ulm, 10 students from 8 different schools in the Ulm area. This includes 19 schools that had already had successful applications in different years, proving that information about the educational enrichment program was passed on within the schools either by the teachers or the students.

Two variants of outcome evaluation were used in the scholarship. The first is the learning journal, mentioned earlier in Section 2.2. Its evaluation makes it possible to continually improve the scholarship concept and adapt it to the needs of students and supervisors.

The narrative self-evaluation in the learning journals shows how the students respond to each task. In one specific example (see Section 4.2.1), a fellow decided to incorporate weather data into a cross-data analysis with commuter rail data to increase forecast accuracy. In the conclusion of the journal, the fellow praised the freedom he had in finding his own solution to expand the data set. He also showed some pride in having found his own way to integrate the weather data into the given database. Such successes greatly enhance the student's confidence in his own abilities and judgment.

The second method of evaluation within the framework of the scholarship was via questionnaires. For this purpose, former scholarship holders were asked about their career development about two years after completing the scholarship. Due to the delay of two years, only the follow-up survey of the first year with a total of 10 scholarship holders is currently available. With a response rate of $70 \%$, an astonishingly large number of former scholarship holders were motivated to respond, considering that the ensuing years involved many personal upheavals including the end of school, taking up studies, or entering professional life, along with the associated relocations.

The survey showed that satisfaction with the scholarship was high in many areas. For the thematic organization of the scholarship, the respondents gave an average grade of $2.0^{23}$; for the meetings with their supervisors, a 2.1; and for the joint meetings they experienced, even a 1.9; in each case without a grade lower than a 3 being given. Only the joint work among the students scored worse, with an average of 2.5. This was because one respondent was not satisfied with his/her scholarship partner and awarded a 5.

The scholarship did particularly well in questions about whether the content was correctly adapted to the performance level of the respondents. Here, the respondents awarded an average of 1.9. Very good scores were also given for the question of whether they would recommend the scholarship to other 11th grade students, with an average of 1.6 (the scores awarded were in the range between one and three).

Meanwhile, all seven respondents are studying at a university, six of them at one in Baden-Württemberg, and one outside Germany. Six are studying a classic STEM subject, one medicine.

The open-ended survey revealed that new skills were acquired during the scholarship. Two respondents said they had learned time

\footnotetext{
${ }^{23}$ German school grades range from 1.0 "very good" to 6.0 "unsatisfactory," with at least 4.0 having to be achieved in order to be promoted to the following grade.
}

and project management, one person highlighted the experience gained in lecture techniques, and another cited working together in a team as a meta-skill learned.

So far, efforts to ensure the quality of the Simulated World offerings have been successful. The project has also received two awards: in 2013 from the Bosch Foundation and in 2014 from the Kreissparkasse Esslingen.

The biggest challenge for the project will be to respond to changing demands of the educational landscape in the post-pandemic period and to bring the existing offerings back into schools. Many schools are signaling that additional educational offerings will have to be scaled back significantly to compensate for cancelled class time. Nevertheless, the project team has already received a number of event requests for the second half of 2021 .

\subsection{Results of the Supercomputing Academy}

To determine the quality of the modules and the satisfaction of the participants at the Supercomputing Academy, participants are asked to take part in regular surveys. Their standardized questions are based on the rules for successful questionnaire design [20]. In accordance with the criteria for learning success [10], the following aspects are assessed:

- $\quad$ Perceived quality of the offering

- Achievement of learning objectives

- Learning behavior: duration of learning, acquisition of confirmations of participation and certificates

- Transfer to the professional environment

- Subjective satisfaction

144 people took part in the eight module runs carried out within the MoeWE project phase. Almost half of the participants attended two or more modules. $105(73 \%)$ qualified certificates of participation (see also Section 2.2) were issued. 86 participants $(60 \%)$ successfully completed the final exam and received a certificate. Five HPC developer awards, seven HPC administrator awards, and four HPC user awards were issued. Six participants received the highest award, HPC Expert.

To determine perceived quality and subjective satisfaction, participants provided feedback on each lesson in weekly surveys. At the end of each module, participants gave a final evaluation of the entire module. The surveys were mostly conducted online.

The results presented below are for the final surveys of all completed modules. Responses were on a 5-point scale. The questions for each criterion are summarized in Table 3. A total of 69 people participated in the surveys.

On average, the quality was rated as good. Likewise, the participants stated on average that they had achieved the learning objectives. Overall, the participants were satisfied with the modules. The learning duration was longer than expected, and $60 \%$ confirmed the transfer of what they had learned to their professional environment.

In the part on the simulation concept of the Simulation module (see also Section 4.1.2), half of the participants needed more than 10 hours for the learning content. The other participants mastered the learning content within five to ten hours. Here it became particularly clear that the participants had different prior knowledge. Therefore, it is important for successful participation to communicate the prerequisites for a module more clearly in the future. 
Table 3: Survey on the quality assurance of the modules of the Supercomputing Academy.

\begin{tabular}{|c|c|}
\hline Criterion & Examples of questions and statements \\
\hline \multirow[t]{2}{*}{ Quality } & $\begin{array}{l}\text { "The common thread was clearly } \\
\text { recognizable." }\end{array}$ \\
\hline & $\begin{array}{l}\text { "The learning content was consistent with } \\
\text { the module description." }\end{array}$ \\
\hline \multirow[t]{2}{*}{ Satisfaction } & $\begin{array}{l}\text { "How satisfied or not satisfied were you with } \\
\text { the learning offered in the module?" }\end{array}$ \\
\hline & "My expectations were met in the module." \\
\hline Learning duration & $\begin{array}{l}\text { "My personal time commitment was higher } \\
\text { than expected." }\end{array}$ \\
\hline $\begin{array}{l}\text { Achieving the learning } \\
\text { objectives }\end{array}$ & "I was able to achieve my set goal." \\
\hline Transfer & $\begin{array}{l}\text { "I can apply the learning content well in my } \\
\text { professional practice." }\end{array}$ \\
\hline
\end{tabular}

The number of participants is still too low to obtain statistically significant figures. Nevertheless, the initial trends are recognizably positive, and the evaluation results for the first run of the modules are very satisfactory overall. The learning content was evaluated as didactically well prepared, which can be seen in the results of the quality and the achievement of the learning objectives.

In addition, the positive trend is confirmed by the numerous participants who attended more than one module and also successfully completed them.

Overall, the modules were very well attended. On average, 18 participants attended the modules. In this particular blended learning format, the maximum limit was set at 20 participants in order to be able to ensure individual support for the learners and to create an optimal learning situation. The current pandemic situation generally favors an online format. However, the number of participants did not increase significantly. The particularly high attendance in the module, "Data: Management and Analysis," can be credited to the fact that this is currently a hot topic. Here, 28 participants were admitted as an exception.

Public relations activities focused on publications of course offerings, the project website, and networking activities. Existing contacts to HLRS' industrial partners were also used to acquire interested participants. Many participants approached the Supercomputing Academy by searching for suitable training courses on the Internet or received recommendations from colleagues and superiors. In the future, even more attention will be paid to direct marketing in order to achieve the maximum with these measures.

\section{THE NEXT STEPS}

Both programs, Simulated Worlds and the Supercomputing Academy, will add new topics to their programs and continuously update and improve the content of their modules and refine their methods.

The continuous development process of Simulated Worlds' offerings must take into account changes in public school curricula. In addition, more topics will be found that can be used to introduce simulations to students. The adaptation of the programming tasks to the different abilities of the students is also an ongoing task. For cost reasons, it must be ensured that only open source software is used. In addition, the program plans to develop new offerings for (vocational) secondary schools and for teachers in training.
Since the beginning in 2021, the Supercomputing Academy is selffinancing through cost-covering registration fees. This poses a major challenge to continue to achieve the good participant numbers seen during the grant-subsidized project phase.

With the relaunch, the modules that previously ran over a period of three months have been divided into smaller modules with a duration of up to six weeks. By focusing on selected content, these smaller modules will meet the individual needs of interested parties and improve the transfer of knowledge and skills to the professional environment.

Content required in several modules, such as instructions on how to use the training cluster and information to provide an understanding of the hardware, will be combined in a basic module and made available to participants for self-study.

In addition, new modules on topics such as machine learning and artificial intelligence are planned. Another consideration is to offer the modules to interested companies as in-house training. In addition, it would be desirable to be able to structure online teaching materials in a more needs-oriented way, for example, by integrating an adaptive learning system [13] that goes beyond the structures provided by the learning management system ILIAS.

\section{SUMMARY}

Simulated Worlds and the Supercomputing Academy (developed during the MoeWE project) achieved the goal of expanding the audience for training in topics related to simulation and HPC. Both projects offer continuing education programs that are tailored to the needs of the respective target groups including students, teachers, and professionals. By consulting with external experts from schools for Simulated Worlds and from industry for MoeWE and the Supercomputing Academy, the project teams succeeded in developing suitable and demand-oriented offerings. Both the scientists and the experts from industry and schools were enthusiastic about the collaboration as the exchange of insights was enriching for everyone involved.

Simulated Worlds has a large portfolio of offerings for students at various levels of knowledge, from lectures in school classrooms to half-day workshops to scholarships that allow students to conduct small research projects at high-performance computing centers alongside their normal school lessons. Teachers are trained to be able to integrate the topic of simulation into their lessons. Evening lectures are offered to the interested public to draw attention to the advantages and limitations of simulation.

Because the Supercomputing Academy / MoeWE targets working people, it uses a blended learning format for teaching. This gives participants as much independence as possible in choosing the time and place in which they learn in order to enable them to learn successfully while managing work and family responsibilities. The continuing education program is modular in structure and offers continuing education opportunities focusing on key topics in simulation and HPC. Currently, the program portfolio consists of seven modules that cover all relevant topics and can be easily expanded. Participants can earn HPC awards depending on the focus of their continuing education when they successfully complete the appropriate modules.

The learning activities related to heat conduction and the Stuttgart commuter rail system demonstrate a wide range of tasks and exercises for participants of Simulated Worlds and the Supercomputing Academy, offering them the opportunity to 
achieve the optimal learning progress in each case through tailored challenges and levels of complexity.

The offerings of both programs are popular with the target groups. Thus, the number of participating schools is steadily increasing. The number of participants in the Supercomputing Academy modules has also risen steadily since the project began, and demand for modules following the project phase is high. Both programs will continue to be offered in the future.

The concepts presented related to these two projects can be transferred very well to other areas of learning because they are independent of the subject matter.

\section{ACKNOWLEDGEMENTS}

Thanks to funding from the Ministry of Science, Research and the Arts of the State of Baden-Württemberg; the Simulated Worlds project has been successfully established and implemented since 2011.

The project MoeWE (2016-2020) was developed and implemented thanks to funding from the Ministry of Science, Research and the Arts of the State of Baden-Württemberg and the European Social Fund (ESF).

Contributors to the work done in the Simulated Worlds project are Dr. Almut Zwölfer, Jochen Barwind, Peter Lürßen, and Adrian Kaiserauer.

Contributors to the work done in the MoeWE project are Dr. Brigitte Lorenz, Dr. Genoveva Schmidtmann, Dr. Nicole Wöhrle, Nicole Prange, Markus Klietmann, Inna Wöckener, Bernd Aumann, Dr. Andreas Wierse, Dr. Norbert Conrad, Christopher Williams, Dr. Ralf Schneider, Dennis Hoppe, Li Zhong, and Dr. Lorenzo Zanon.

\section{REFERENCES}

[1] Acatech and Körber-Stiftung (Ed.). 2021. MINT Nachwuchsbarometer 2021. (May 6, 2021). Retrieved July 9, 2021 from: https://www.acatech.de/publikation/mintnachwuchsbarometer-2021/download-pdf?lang=de

[2] Benjamin S. Bloom, Max D. Engelhart, Edward J. Furst, Walker H. Hill, and David R. Krathwohl. 1956. Taxonomy of educational objectives: The classification of educational goals. Handbook I: Cognitive domain. David McKay Company, New York.

[3] Charles Xie. 2012. Interactive Heat Transfer Simulations for Everyone. In The Physics Teacher 50, 237 (April 2012), American Association of Physics Teachers (Ed.). DOI: https://doi.org/10.1119/1.3694080

[4] Christoph Meier. 2019. KI-basierte, adaptive Lernumgebungen (Beitrag Handbuch E-Learning). (July 2019). Retrieved July 9, 2021 from https://www.scil.ch/2019/07/05/ki-basierte-adaptivelernumgebungen-beitrag-fuer-handbuch-e-learning/

[5] Freydis Vogel and Frank Fischer. 2018. Computerunterstütztes kollaboratives Lernen. Lernen mit Bildungstechnologien. Helmut Niegemann and Armin Weinberger (Eds.). Springer Reference Psychologie. Springer, Berlin, Heidelberg. 1-24. DOI: https://doi.org/10.1007/978-3-662-54373-3_3-1

[6] Gilbert Geefrath and Hans-Georg Weigand. 2012. Simulieren: Mit Modellen experimentieren. Mathematik lehren, Pädagogische Zeitschriften (in Zusammenarbeit mit Klett) 174 (October 2012), 2-6.

[7] Horst Otto Mayer, Johannes Hertnagel, and Heidi Weber. 2009. Lernzielüberprüfung im eLearning. Oldenbourg Wissenschaftsverlag, München. DOI: https://doi.org/10.1524/9783486848984

[8] Jörg Hilpert, Rüdiger Berlich, Peter Lürßen, Almut Zwölfer and Jochen Barwind. 2015. Teaching Simulations and High Performance Computing at Secondary Schools in the German State of Baden-Württemberg. In Proceedings of the 2015 IEEE International Parallel and Distributed

Processing Symposium Workshop, May 25-29, 2015, Hyderabad, India, 731-738. DOI: https://doi.org/10.1109/IPDPSW.2015.61

[9] Juan Chen and Li Shen. 2018. Design of Paper CPU Project to Improve Student Understanding of CPU Working Principle. In Proceedings of ACMTuring Celebration Conference - China (TURC 2018), May 19-20, 2018, Shanghai, China, 96-102. DOI: https://doi.org/10.1145/3210713.3210735

[10] Lorin W. Anderson and David R. Krathwohl (Eds.). 2001. A taxonomy for learning, teaching, and assessing: A revision of Bloom's taxonomy of educational objectives. Longman, White Plains, NY.

[11] Maren Hattebuhr, Martin Frank and Christina Roeckerath. 2018. Komplexe Modellierung: Trump gegen die Wissenschaft - Gibt es den Klimawandel wirklich? Gesellschaft für Didaktik der Mathematik, Beiträge zum Mathematikunterricht (2018), 731-734. Retrieved June 22, 2021 from: https://eldorado.tudortmund.de/bitstream/2003/37393/1/BzMU18_HATTEBU HR_Klimamodellierung.pdf

[12] Maria Opfermann, Tim N. Höffler and Annett Schmeck. 2019. Lernen mit Medien: ein Überblick. Lernen mit Bildungstechnologien. Helmut Niegemann and Armin Weinberger (Eds.) Springer Reference Psychologie. Springer, Berlin, Heidelberg. 1-14. Retrieved July 9, 2021 from https://link.springer.com/content/pdf/10.1007\%2F9783-662-54373-3_2-1.pdf DOI: https://doi.org/10.1007/978-3662-54373-3_2-1

[13] Maria Reichelt, Frauke Kämmerer and Ludwig Finster. 2019. Lehrziele und Kompetenzmodelle beim E-Learning. Lernen mit Bildungstechnologien, Helmut Niegemann and Armin Weinberger (Eds.). Springer Reference Psychologie. Springer, Berlin, Heidelberg. 1-16. DOI: https://doi.org/10.1007/978-3-662-54373-3_15-1

[14] Marie des Jardins and Michael Littman. 2010. Broadening Student Enthusiasm for Computer Science with a Great Insights Course. In SIGCSE '10: Proceedings of the 41st ACM technical symposium on Computer science education, March 2010, New York, USA, 157-161. DOI: https://doi.org/10.1145/1734263.1734317

[15] Marlen Schulz. 2012. Quick and easy?! Fokusgruppen in der angewandten Sozialwissenschaft, Fokusgruppen in der empirischen Sozialwissenschaft: Von der Konzeption bis zur Auswertung, Marlen Schulz, Birgit Mack and Ortwin Renn (Eds.). Springer VS, Wiesbaden, 9-22. DOI: https://doi.org/10.1007/978-3-531-19397-7_1 
[16] Michael Kerres. 2018. Chapter 3 - Gründe für das Lernen mit Medien. Mediendidaktik. De Gruyter, Oldenburg, 87126. DOI: https://doi.org/10.1515/9783110456837-099

[17] Michael Kerres. 2002. Online-und Präsenzelemente in hybriden Lernarrangements kombinieren. Handbuch ELearning. Andreas Hohenstein and Karl Wilbers (Eds.). Deutscher Wirtschaftsdienst, Köln, 7-12.

[18] Ministerium für Kultus, Jugend und Sport BadenWürttemberg (Ed.). 2004. Bildungsplan 2004: Allgemein bildendes Gymnasium, 400-402. Retrieved June 22, 2021 from: http://www.bildungsplaenebw.de/site/bildungsplan/get/documents_E978621370/lsbw/Bi ldungsplaene/Bildungsplaene2004/Bildungsstandards/Gymnasium_Bildungsplan_Gesamt. pdf

[19] Miriam Venn. 2011. Lerntagebücher in der Hochschule. In Journal Hochschuldidaktik 1, 9-12. Retrieved October 10, 2016 from: http://www.zhb.tu-dortmund.de/hd/journalhd/20111/journalhd20111_venn.pdf
[20] OECD, European Union and UNESCO Institute for Statistics (Eds.). 2015. ISCED 2011 Operational Manual: Guidelines for Classifying National Education Programmes and Related Qualifications. (March 20, 2015). OECD Publishing. DOI: http://dx.doi.org/10.1787/9789264228368-en

[21] Teaching \& Learning Academy. 2019. 1.3 Learning Outcomes. Wirtschaftsuniversität Wien (Ed.) (November 2019). Retrieved June 22, 2021 from: https://learn.wu.ac.at/open/tlac/learningoutcomes

[22] Rolf Porst. 2000. Question Wording — zur Formulierung von Fragebogen-Fragen. GESIS-How-to, 2, Zentrum für Umfragen, Methoden und Analysen - ZUMA (Ed.), Mannheim. Retrieved November 12, 2020 from: https://nbnresolving.org/urn:nbn:de:0168-ssoar-201334

[23] Thomas J. Cortina. 2007. An Introduction to Computer Science for Non-Majors Using Principles of Computation. ACM SIGCSE Bulletin 39, 1 (March 7, 2007), 218-222. DOI: https://doi.org/10.1145/1227504.1227387 